\title{
A comparison of drinking in the normal and nephrectomized hooded rat ${ }^{1,2}$
}

MATTHEW J. WAYNER AND JULIA J, BURGER

SYRACUSE UNIVERSITY

Normal ad lib drinking was studied in food deprived nephrectomized, sham operated, and normal rats under the same environmental conditions. Nephrectomized animals drank normal amounts of water until they developed obvious symptoms of uremia at about $60 \mathrm{hr}$.

Drinking in the rat is directly related to water loss, within limits, and indirectly related to other factors as relative concentration of extracellular ions, blood volume, etc. (Adolph, 1964). In the laboratory it is relatively easy to make a rat drink water by increasing its extracellular ionic concentration (Kutscher, 1966). Drinking will occur rapidly following intravenous, intraarterial, intraperitoneal, or subcutaneous injections of hypertonic saline. If moderate amounts of hypertonic saline are administered, the animal drinks and is physiologically capable of excreting the salt load without any apparent deleterious effects. Renal regulation begins very rapidly and, as the rat is a slow drinker, the relationship between water intake, blood tonicity, and blood volume is complicated by the loss of electrolytes in the continuous formation of urine. Fitzsimons (1961) therefore eliminated this complicating factor in his experiments on drinking by studying nephrectomized rats.

Little additional information is available on normal drinking in nephrectomized rats. Linazasoro, Diaz, \& Mendoza (1954) reported a reduction in ad lib water drinking in nephrectomized rats which they attributed to a lack in the "sensation of thirst." Fitzsimons (1961) did not find a lack in the "sensation of thirst" and nephrectomized rats drank more water than normal animals following intravenous injections of hypertonic solutions. Because of the particular experimental procedures which Fitzsimons (1961) employed it is difficult to compare the ad lib drinking in nephrectomized animals with normal rats. Our own preliminary results indicated that water drinking in nephrectomized rats was variable unless animals were deprived of food prior to and following the nephrectomy. Apparently, absorption of various ions from food in the gastrointestinal tract had been an uncontrolled variable.

The purpose of the present experiment was to compare ad lib drinking in food deprived normal, sham operated, and nephrectomized rats under standard laboratory conditions. Results indicated no significant differences between the three groups for the first $60 \mathrm{hr}$.

Animals

Animals were female hooded rats approximately four months in age selected to reduce body weight variability from our own colony. Three groups of 10 animals each were studied.

\section{Procedure}

Animals were selected on the basis of body weight from the main colony, moved into a temperature controlled $\left(21^{\circ} \mathrm{C} \pm 1^{\circ}\right)$ experimental room, where they were placed into individual plastic boxes fitted with stainless steel drinking spouts and $100 \mathrm{cc}$ eudiometer tubes. They were food deprived for $48 \mathrm{hr}$. and water was present at all times. Following food deprivation, one group of animals, the normal group, continued living in the individual boxes without food but water present for the next $72 \mathrm{hr}$. Animals of the second group, the nephrectomized group, were etherized for $15 \mathrm{~min}$. and a bilateral nephrectomy (kidneys were actually removed) was performed. Animals were then replaced in the individual boxes without food but water present for the next $72 \mathrm{hr}$. The third group, sham-operated, were subjected to the same procedures as the second group (nephrectomized) except that their kidneys were not removed. Water intakes and body weights of each animal were recorded every $12 \mathrm{hr}$. for a total of $72 \mathrm{hr}$. Results

The uremic syndrome is difficult to define (Teschan et al, 1964) especially during the early hours following nephrectomy when animals have not fully recovered from the anesthetic and surgical shock. Sham-operated animals appeared to be fully recovered within $12 \mathrm{hr}$. and were active, groomed, appeared to be easily aroused and were alert. Nephrectomized animals required a longer initial period to recover from the surgery but appeared normal within $24 \mathrm{hr}$. Obvious differences in the overt behavior of the nephrectomized animals began to appear at about $60 \mathrm{hr}$. following surgery. At this time they appeared to be lethargic, spontaneous activity decreased, animals appeared drowsy and sleep was prolonged, animals did not groom, and they were difficult to arouse by means of the usual emotional stimuli. Other behavioral symptoms, increase in maze running time and errors, apparently occur much earlier (Essman, 1960). More quantitative measures of this type were not obtained in this experiment. All animals survived the additional $72 \mathrm{hr}$. of food deprivation and they were then sacrificed. Post mortem examination revealed some increase in fluid in the respiratory passages, more dilute saliva, no pronounced pulmonary edema, or excessive fluid in the peritoneum, the blood was more dilute, and in some cases evidence of fluid leakage from the anus was observed. 

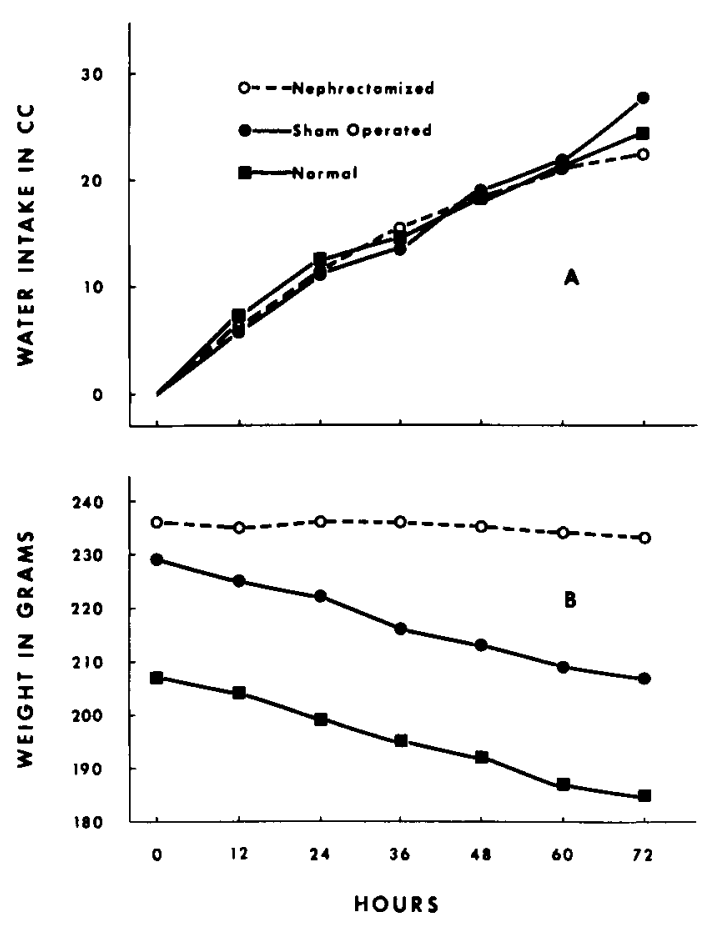

Fig. 1. Comparison of drinking in the normal and nephrectomized hooded rat.

Mean cumulative water intakes and body weights measured at $12 \mathrm{hr}$. intervals for all three groups are presented graphically in Parts A and B of Fig. 1. A multifactor analysis of variance for repeated measures on the same Ss was performed on the mean water intakes for each $12 \mathrm{hr}$. period up to and including 60 $\mathrm{hr}$. The differences in mean $12 \mathrm{hr}$. water intakes between the three groups were not significant and the $F$ was considerably less than one. The mean $12 \mathrm{hr}$. intakes from 12 to $60 \mathrm{hr}$. did decrease significantly $(\mathrm{F}=17.47 ; \mathrm{df}=4 / 108 ; \propto=.01)$ as expected. The $12 \mathrm{hr}$. mean water intakes for each of the $12 \mathrm{hr}$. periods up to $60 \mathrm{hr}$. are presented in Table 1 . The interaction was not significant $(F=1.42 ; d f=8 / 108)$. As the nephrectomized animals definitely began to show symptoms of uremia from 60 through $72 \mathrm{hr}$. and because the drinking in the three groups was obviously different at $72 \mathrm{hr}$. (Part A of Fig. 1), the mean water intakes from 60 to

Table 1.

Twelve hr. mean water intakes in $\mathrm{ml}$ for each group for $69 \mathrm{hr}$.

\begin{tabular}{llllll} 
& 12 & 24 & 36 & 48 & $60 \mathrm{hr}$. \\
\hline Nephrectomized & $6.1 \mathrm{ml}$ & 5.1 & 4.1 & 2.9 & 2.6 \\
Sham-operated & 5.8 & 5.4 & 2.4 & 4.3 & 2.6 \\
Normal & 7.1 & 5.2 & 2.2 & 3.7 & 2.5 \\
\hline
\end{tabular}

$72 \mathrm{hr}$. were analyzed separately by a one-way analysis of variance. The differences between the three groups were significant $(F=14.02 ; d f=2 / 27 ; \propto=.05)$ and substantiate the impression one obtains from the overt behavioral data that the uremia has become critical. The nephrectomized animals drink considerably less water at this time which can probably be attributed to poor physiological conditions in general rather than to any specific effect on drinking itself.

An examination of the mean body weights for each group (Part B of Fig. 1) reveals that the nephrectomized animals lost $3 \mathrm{gm}$ during the $72 \mathrm{hr}$. whereas the weight losses for the sham-operated and normal animals were exactly the same at $22 \mathrm{gm}$. The mean weight losses up to $60 \mathrm{hr}$. were $2 \mathrm{gm}$ for the nephrectomized and $20 \mathrm{gm}$ for the other two groups. The mean cumulative water intakes for each group at $60 \mathrm{hr}$. were for all practical purposes identical: nephrectomized, $20.8 \mathrm{ml}$; shamoperated, $21.4 \mathrm{ml}$; and normal, $20.7 \mathrm{ml}$. Therefore the net retention of the water ingested for the nephrectomized animals, assuming all other conditions for the three groups were identical, was approximately $19 \mathrm{ml}$. Discussion

Results are obvious and demonstrate that food deprived nephrectomized rats drink amounts of water comparable to normal rats under identical laboratory conditions. These results do not support the earlier work of Linazasoro, Diaz, \& Mendoza (1954) but tend to confirm the work of Fitzsimons (1961). A more systematic analysis of blood sodium, potassium, osmolality, and the salt arousal of drinking in nephrectomized rats will be published in the future.

\section{References}

Adolph, E. F. Regulation of body water content by water regulation. In M. J. Wayner (Ed.), Thirst in the regulation of body water. London: Pergamon, 1964. Pp. 5-17.

Essman, W. B. Correlates of behavioral deficit with an experimental induction of acute renal failure in rats. Clin. Res., 1960, 8, 175.

Fitzsimons, J. T. Drinking by nephrectomized rats injected with various substances. J. Physiol., 1961, 155, 563-579.

Kutscher, C. L. Effect of hypertonic saline injections and water deprivation on drinking, serum osmolality, and gut water. Physiol. Behav., 1966, 1, 259-268.

Linazasoro, J., Diaz, C. J., \& Mendoza, H. C. The kidney and thirst regulation. Bull. Inst. Med. Res., Madtid. 1954, 7, 53-61.

Teschan, P. E., Murphy, G. P., \& Sharp, J. C. Investigation of behavioral performance during urine reinfusion in the male primate. Amer. J. Physiol., 1964, 206, 510-514.

\section{Notes}

1. Supported by a grant from the National Science Foundation No. GB-2119.

2. The assistance of Miss Sandra Mandelar is gratefully acknowledged. 